\title{
Concomitant infection with Mycobacterium leprae and Mycobacterium tuberculosis in an immunocompetent patient: A rare association
}

\section{Savita Arya, Ramesh Kushwaha, Suresh Jain, Motilal Bunkar ${ }^{1}$}

Departments of Dermatology, Venereology and Leprology and ${ }^{1}$ Pulmonary Medicine, Government Medical College, Kota, Rajasthan, India

Address for the Correspondence: Dr. Savita Arya,

Room No. 28, P.G. Hostel, New Medical College Campus, Kota - 324 010, Rajasthan, India.

E-mail: savita2009arya@ gmail.com

\section{Access this article online}

Website: www.ijmedph.org

DOI: $10.4103 / 2230-8598.179765$

Quick response code:

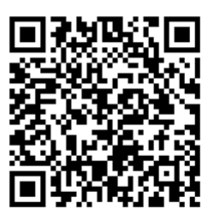

Leprosy is a chronic infectious disease caused by Mycobacterium leprae, a microorganism that usually affects skin and nerves. Although it is well-controlled by multidrug therapy but the disease may be aggravated by acute inflammatory reaction that causes permanent tissue damage, particularly to peripheral nerves. Cutaneous tuberculosis (CT) is a variant of extrapulmonary tuberculosis. Both mycobacterial infections are endemic in developing countries like India, but the simultaneous occurrence of CT and leprosy is very rarely reported. Here, we are reporting a case of borderline lepromatous leprosy and CT (lupus vulgaris) co-infection in an immunocompetent patient, diagnosed simultaneously and managed accordingly.

Key words: Borderline lepromatous leprosy, cutaneous tuberculosis, extrapulmonary tuberculosis, multidrug therapy

\section{INTRODUCTION}

Both tuberculosis (TB) and leprosy are chronic granulomatous disease caused by Mycobacterium tuberculosis and Mycobacterium leprae, respectively. The simultaneous occurrence of two mycobacterial infection in a single immunocompetent person is very unusual occurrence even in endemic countries like India also. Extrapulmonary TB (EPTB) is an emerging problem as they have a diagnostic dilemma and management controversy. In India, the incidence of EPTB ranges from $20 \%$ to $30 \% \cdot{ }^{[1]}$ Cutaneous tuberculosis (CT), a variant of EPTB, accounts only $1.5 \%$ of all cases. The incidence of concomitant infection (leprosy and CT) is $3.2 \%$ in Indian population. The simultaneous occurrence of both infections is based on the transmission dynamics, means the higher reproductive rate of tubercular Bacilli than the lepra Bacilli and the degree of cross-immunity they offer in an individual. ${ }^{[2]}$ Here, we are discussing an uncommon case of lupus vulgaris with borderline lepromatous (BL) leprosy diagnosed simultaneously, and their complex relationship is discussed.

\section{CASE REPORT}

A 65-year-old female was reported to dermatology outpatient department with multiple ill-defined, erythematous, hypoesthetic lesions with coppery hue present over extensor surface of upper extremities, anterior aspect of the left thigh, back, and trunk since 8 years [Figure 1a]. There was a well demarcated, irregularly bordered, nontender, slight erythematous to scaly plaque extending from the right cheek to nose, and left cheek since 2 years. The lesion was progressive and causing facial scarring resultant

This is an open access article distributed under the terms of the Creative Commons AttributionNonCommercial-ShareAlike 3.0 License, which allows others to remix, tweak, and build upon the work non-commercially, as long as the author is credited and the new creations are licensed under the identical terms.

For reprints contact: reprints@medknow.com

How to cite this article: Arya S, Kushwaha R, Jain S, Bunkar M. Concomitant infection with Mycobacterium leprae and Mycobacterium tuberculosis in an immunocompetent patient: A rare association. Int J Med Public Health 2016;6:50-2. 
into ectropion [Figure 1b]. On examination, the right madarosis was present with thickened right ulnar and infraorbital nerve. The systemic examination was normal including respiratory system. No personal or family history of pulmonary TB. She also denied for hypertension, diabetes mellitus, and any other immunocompromised state.

Routine hematological and biochemical test were within normal limits including serological tests for Leishmania, syphilis, and human immunodeficiency virus. Skiagram chest posterior-anterior view was also normal. Slit smear examination from both ear-lobules revealed bacteriological index $4+$ with $28 \%$ morphological index [Figure 2a]. Skin Biopsy from the right forearm showing diffuse branching granuloma consisted of macrophages and dermal infiltrate composed of vacuolated histiocytes suggestive of BL leprosy [Figure 2b].

Punch biopsy from face showed normal epidermis with focal parakeratosis and noncaseating granulomas consisting of epithelioid histiocytes, plasmocytes, and Langhans giant cells in the dermis suggestive of lupus vulgaris [Figure 3], which was further confirmed by positive TB polymerase chain reaction (PCR). Clinical and histopathological features confirm two separate diagnoses in a single immunocompetent person. We started directly observed short course chemotherapy (DOTS) CAT-I with multidrug therapy (MDT) without rifampicin as long as the CAT-I regimen contains rifampicin. After completion of treatment, facial lesions of lupus vulgaris regressed and healed completely while skin lesions of BL leprosy showed significant improvement [Figure $4 \mathrm{a}$ and b].

\section{DISCUSSION}

The occurrence of leprosy and pulmonary TB co-infection first time reported by Relvich ${ }^{[3]}$ in 1954, after that it was elaborated by many authors. The occurrence of leprosy along with EPTB including lupus vulgaris is very rare (incidence $\sim 3.2 \%$ ) and was first described by Ganapati et al..$^{[4]}$ in 1976 . The simultaneous infection of both mycobacterial infections was initially reported by Pinto et al. in 1991. ${ }^{[5]}$

The exact nature of relationship between leprosy and TB remains enigmatic. They share similar characteristic such as both diseases being caused by Gram-positive, acid-fast mycobacteria that are characterized by chronic granulomatous reaction and host-specific cell-mediated immune response, which shows a vibrant role in defining the clinical spectrum. They share common antigens as evidenced by conversion of tuberculin and lepromin intradermal tests after administration of Bacillus Calmette-Guérin vaccine. ${ }^{[6]}$

An inherent impaired immunity against both mycobacterial organisms has been postulated as the etiology for dual infection, associated with high mortality, and major morbidity. Leprosy leads to depressed cell-mediated immunity which may either reactivate the latent tubercular infection or make the person susceptible for new infection. Defect in Toll-like receptor 2 may blunt the triggering of host defense mechanism. Reduced inducible chemokine ligand-2
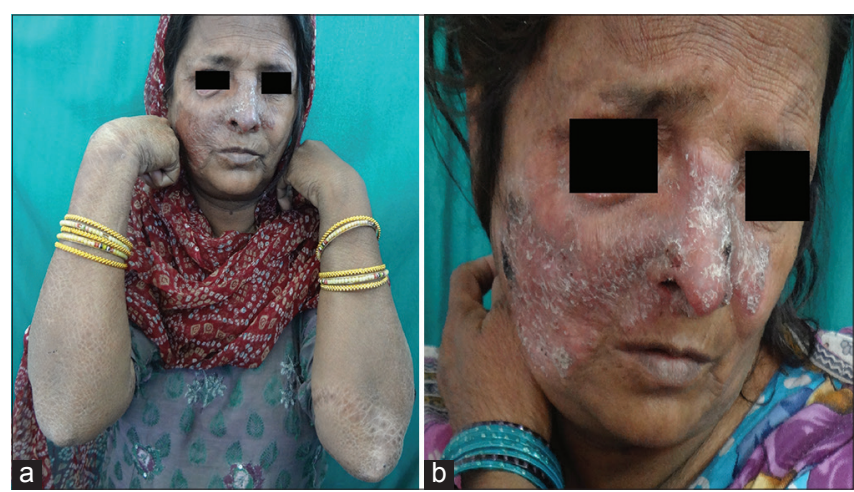

Figure 1: (a) Multiple ill-defined, erythematous, and hypoesthetic lesions with coppery hue present over extensor surface of upper extremities. (b) Well- demarcated, irregularly bordered, nontender, slight erythematous to scaly plaque extending from right cheek to nose, and left cheek
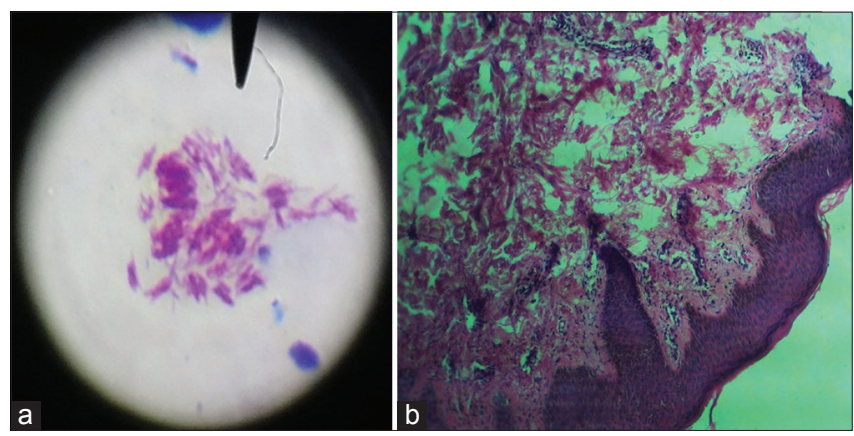

Figure 2: (a) Slit smear examination from both ear-lobules revealed bacteriological index $4+$ with $28 \%$ morphological index ( $\times 100$, oil immersion). (b) Skin biopsy from the right forearm showing diffuse branching granuloma consisted of macrophages and dermal infiltrate composed of vacuolated histiocytes suggestive of borderline lepromatous leprosy $(\mathrm{H}$ and $\mathrm{E}, \times 40)$

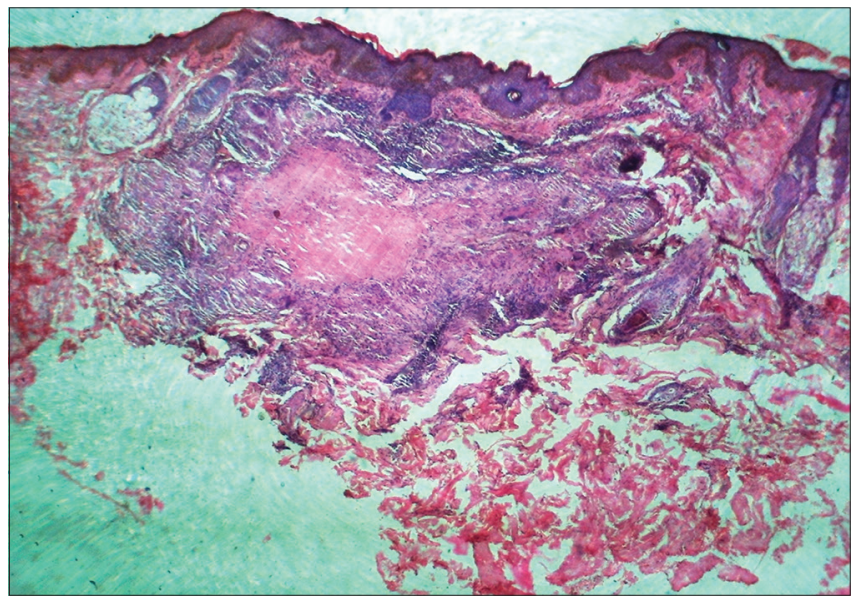

Figure 3: Punch biopsy from face showed normal epidermis with focal parakeratosis and noncaseating granulomas consisting of epithelioid histiocytes, plasmocytes and Langhans giant cells in the dermis suggestive of lupus vulgaris $(\mathrm{H}$ and $\mathrm{E}, \times 40)$

and tumor necrosis factor (TNF) alpha responses in lepromatous leprosy contribute to unrestricted growth and dissemination of 


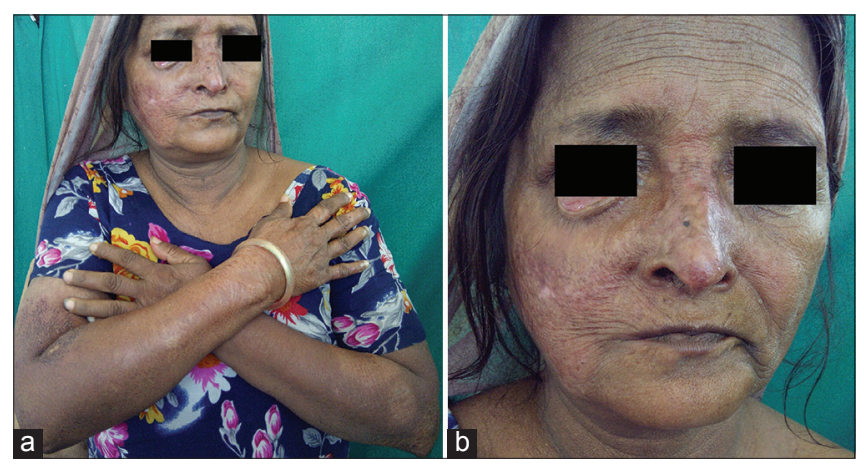

Figure 4: $(a$ and b) After completion of treatment, facial lesions of lupus vulgaris regressed and healed completely while skin lesions of BL leprosy showed significant improvement

tubercle Bacilli. ${ }^{[7]} \mathrm{CD} 4+\mathrm{T}$-cells, the cytokines-interleukin-12, interferon-gamma, and TNF-alpha are precarious in the control of M. tuberculosis and M. leprae infections, but the host factors responsible for protection from infection to individuals are still unclear. ${ }^{[8]}$

The incubation period of both the infection differs as in leprosy it varies from 6 months to many years while in TB it ranges from few weeks to months. The duration of the gap between the development of leprosy and TB varied between 2 months to $10-15$ years $^{[0]}$ as in our case it was 6 years. Diagnosis of leprosy was established by slit skin smear and histopathological examination while computed tomography confirmed by histology. Management of TB in leprosy co-infection does not change; with the same WHO treatment categorization, i.e., CAT-I along with MDT. The MDT regimen should omit rifampicin as long as the TB regimen contains rifampicin. ${ }^{[10]}$

\section{CONCLUSION}

Every patient of leprosy should be screened for TB (either pulmonary or EPTB) in an endemic area like India. Sometimes, CT and leprosy share a common clinical picture. Hence, an early and prompt suspicion of these two diseases simultaneously in a single person can change the outcome and prognosis.

\section{Declaration of patient consent}

The authors certify that they have obtained all appropriate patient consent forms. In the form the patient(s) has/have given his/her/ their consent for his/her/their images and other clinical information to be reported in the journal. The patients understand that their names and initials will not be published and due efforts will be made to conceal their identity, but anonymity cannot be guaranteed.

\section{Financial support and sponsorship}

Nil.

\section{Conflicts of interest}

There are no conflicts of interest.

\section{REFERENCES}

1. Takhar R, Bunkar ML, Jangid V, Saxena A. Bilateral parotid gland tuberculosis: A rare occurrence. Egypt J Chest Dis Tuberc 2015;64:653-6.

2. Choubey S, Sharma M, Agrawal B. Pulmonary tuberculosis and lepromatous leprosy co-infection in a single individual: A Case report. J Assoc Chest Physicians 2014;2:40-2.

3. Relvich AL. The treatment of tuberculosis in leprosy patients. Lepr Rev 1954;25:179-86.

4. Ganapati R, Deshpande DH, Chulawala RG. Some interesting disease combinations - Report on two cases. Lepr India 1976;48:428.

5. Pinto J, Pai GS, Kamath N. Cutaneous tuberculosis and leprosy. Indian J Dermatol Venereol Leprol 1991;57:303-4.

6. Kumaran MS, Dogra S, Kaur I, Kumar B. Lichen scrofulosorum in a patient with lepromatous leprosy after BCG immunotherapy. Lepr Rev 2005;76:170-4.

7. Hasan Z, Jamil B, Zaidi I, Zafar S, Khan AA, Hussain R. Elevated serum CCL2 concomitant with a reduced mycobacterium-induced response leads to disease dissemination in leprosy. Scand J Immunol 2006;63:241-7.

8. O'Garra A, Redford PS, McNab FW, Bloom Cl, Wilkinson RJ, Berry MP. The immune response in tuberculosis. Annu Rev Immunol 2013;31:475-527.

9. Agarwal DK, Mehta AR, Sharma AP, Sural S, Kumar A, Mehta B, et al. Coinfection with leprosy and tuberculosis in a renal transplant recipient. Nephrol Dial Transplant 2000;15:1720-1.

10. Available from: http://www.idi-makerere. com/resources/ doc_view/55-2010-national-tuberculosis-and-leprosy -programme-uganda-ministry-of-health. [Last accessed on 2016 Jan 31]. 